\title{
PENGARUH BUDAYA ORGANISASI TERHADAP PERILAKU IHSAN PERAWAT MELALUI PERSONAL VALUES PADA RUMAHSAKIT ISLAM GONDANGLEGI MALANG
}

\author{
Moh Adi Hilmi \\ Ilfi Nurdiana \\ Fakultas Ekonomi Universitas Negeri Maulana Malik Ibrahim Malang \\ Email:faza.hilmi@gmail.com
}

\begin{abstract}
Every organization must have a culture that guides the organization. Someone will work seriously if in a comfortable atmosphere and working environment. The purpose of this study was to find out how big in the organizational culture directly or indirectly that influenced the Nurses Ihsan Behavior at Gondanglegi Islamic Hospital of Malang. Type of research used a quantitative research model with descriptive or survey approach that aimed at testing the predefined hypothesis. The object of this study was conducted at Gondanglegi Islamic Hospital of Malang. The sample used 72 respondents with non-probability sampling technique. The result indicated that the organizational Culture had direct and significant effect to Nurses Ihsan Behavior. The Organizational Culture had significant effect to Ihsan Behavior through Personal Values. It meant that if in the organizational culture and personal values increase, then the Nurses Ihsan Behavior will also increase variable.
\end{abstract}

Keywords: Organizational Culture, Personal Values, Nurses Ihsan Behavior

Manajemen sumber daya manusia (MSDM) merupakan salah satu bidang strategi dari organisasi. Manajemen sumber daya manusia harus di pandang sebagai perluasan dari pandangan tradisional untuk mengelola orang-orang secara efektif dan terkoordinir, untuk itu organisasi tersebut membutuhkan pengetahuan tentang perilaku manusia dan kemampuan dalam mengelola suatu organisasi. Untuk mengetahuinya maka perusahaan perlu menganalisis serta memperhatikan setiap kebutuhan-kebutuhan yang diperlukan oleh para pegawainya, diantaranya adalah terbentuknya suatu budaya organisasi yang baik dan terkoordinir.

Setiap organisasi pasti memiliki kebudayaan yang menjadi pedoman dalam berorganisasi, karena budaya organisasi merupakan sebuah identitas dari setiap organisasi, maka dari itu perbedaan budaya tersebut mampu memberikan keragaman budaya yang nantinya akan memberikan efek yang positif bagi organisasi atau bahkan sebaliknya akan memberikan dampak yang buruk terhadap organisasi tersebut. Menurut Wirawan (2007) budaya organisasi merupakan pola kepercayaan dan harapan yang dianut oleh anggota organisasi. Kepercayaan dan harapan tersebut menghasilkan nilai-nilai yang dengan kuat mem- bentuk perilaku para individu dan kelompok-kelompok anggota organisasi.

Nilai sebagai sebuah pegangan yang membentuk pandangan dunia (world view) manusia dapat mengarahkan hidup manusia dalam memenuhi hajatnya secara wajar, sesuai dengan fitrahnya tanpa menepikan apalagi menafikan hak-hak dan kewajiban sosial disamping hak dan kewajiban individual. Menurut Robbins (2015) memaknai nilai (value) yaitu keyakinan dasar bahwa sebuah mode tindakan spesifik atau akhir dari keberadaan lebih diinginkan secara pribadi atau sosial dibandingkan mode tindakan atau akhir keberadaan lawannya atau kebalikannya.

Perilaku Ihsan secara harfiah berarti untuk melakukannya dengan baik atau untuk melakukan yang terbaik. Dalam bahasa modern Perilaku Ihsan adalah dimulai dari asumsi bahwa Perilaku Ihsan dipahami sebagai doktrin atau konsep yang mendukung etika kerja yang baik. Dalam perspektif ini, perilaku perlu mengoptimalkan kerja dan melakukan perbuatan baik dan melaksanakan tugas sesuai dengan kinerja yang berkualitas tinggi (Ismail, 2011).

Rumah Sakit adalah salah satu bentuk layanan yang dapat disediakan oleh pemerintah atau swasta. 
Pemerintah sendiri terus berupaya untuk memberikan pelayanan di rumah sakit kepada masyarakat dengan sebaik-baiknya. Namun, kurangnya sumber daya membuat pemerintah tidak mampu melayani semua kebutuhan masyarakat dengan benar. Hal ini memberi kesempatan bagi sektor swasta untuk membangun rumah sakit. Namun, Rumah Sakit itu harus mampu menangkap perbedaan dan kebutuhan pengguna jasa sambil membantu untuk memenuhi berbagai kebutuhan masyarakat (Handayanto dkk, 2014). Rumah Sakit Islam (RSI) Gondanglegi-Malang merupakan rumah sakit Islam swasta di bawah naungan Yayasan Kesejahteraan Islam Gondanglegi. Selain itu, Rumah Sakit Islam Gondanglegi senantiasa memegang motto: Ikhlas dan profesional dalam pelayanan. Seperti kebanyakan Rumah Sakit Islam saat ini, Islam hanya menjadi artefak, sementara nilai-nilai dan asumsi dicampur antara budaya kontemporer dan Islam, bahkan sulit untuk membedakannya (Handayanto dkk, 2014).

Menurut hasil penelitian Handayanto dkk (2014) bahwa terdapat pengaruh yang signifikan budaya organisasi terhadap personal values dan perilaku ihsan. Sedangkan penelitian Ihsan (2016) menghasilkan bahwa budaya organisasi berpengaruh secara signifikan terhadap perilaku individu.

Namun, hasil penelitian Handayanto dkk (2014) menyatakan bahwa budaya organisasi tidak berpengaruh secara signifikan terhadap perilaku ihsan perawat. Menurut Trevino dkk (2006) dalam Penelitian Thomas (2013) mengatakan bahwa budaya organisasi memiliki efek langsung dan tidak langsung terhadap perilaku individu yang di mediasi (intervening) oleh personal values. Selain itu, dalam penelitian Narwal (2016) menjelaskan bahwa budaya organisasi dan nilai-nilai pribadi tetap terkait erat dalam membimbing perilaku individu. Dalam artian bahwa nilai-nilai pribadi sebagai mediasi (intervening) antara budaya organisasi dengan perilaku baik/buruknya individu. Dari uraian di atas, masih terdapat kontradiksi penelitian, sehingga penelitian ini bertujuan untuk meneliti pengaruh langsung Budaya Organisasi Terhadap Perilaku Ihsan serta menguji pengaruh Budaya Organisasi Secara Tidak Langsung Terhadap Perilaku Ihsan Melalui Personal Values.

\section{Budaya Organisasi}

Menurut Wirawan (2007) Budaya organisasi merupakan pola kepercayaan dan harapan yang dianut oleh anggota organisasi. Kepercayaan dan harapan tersebut menghasilkan nilai-nilai yang dengan kuat membentuk perilaku para individu dan kelompokkelompok anggota organisasi. Sedangkan Menurut Luthans (2006) Budaya Organisasi merupakan norma-norma dan nilai-nilai yang mengarahkan perilaku anggota organisasi.

Menurut Dessler (2006) Budaya Organisasi adalah karakteristik nilai-nilai, tradisi dan perilaku karyawan dalam perusahaan. Setiap anggota akan berperilaku sesuai dengan budaya yang berlaku agar diterima oleh lingkungannya. Umar (2010) mengatakan Budaya organisasi adalah suatu sistem nilai dan keyakinan bersama yang diambil dari pola kebiasaan dan falsafah dasar pendirinya yang kemudian berinteraksi menjadi norma-norma, dimana norma tersebut dipakai sebagai pedoman cara berpikir dan bertindak dalam upaya mencapai tujuan bersama.

Dari beberapa pengertian di atas peneliti dapat menyimpulkan bahwa budaya organisasi merupakan suatu nilai-nilai dan norma-norma yang dijadikan pedoman atau acuan cara berfikir dan bertindak bagi suatu organisasi untuk mencapai suatu tujuan yang sudah ditetapkan.

Dalam Islam, dicontohkan Rasulullah Saw mengenai budaya tepat waktu. Dijelaskan bahwa waktu adalah sesuatu yang sangat berharga yang tidak boleh diabaikan. Rasulullah Saw. Memberi contoh bagaimana beliau menyikapi ketepatan waktu, kemudian diikuti oleh para sahabat beliau. Akhirnya, sahabat menyadari dan terbiasa untuk menghargai waktu.

Dalam hadis riwayat Imam Baihaqi, Rasulullah Saw. Bersabda yang artinya

"Siapkan lima sebelum (datangnya) lima. Masa hidupnya sebelum datang waktu matimu, masa sehatmu sebelum datang waktu sakitmu, masa senggangmu sebelum datang masa sibukmu. Masa mudamu sebelum datang masa tuamu, dan masa kayamu sebelum datang masa miskinmu." (Fahmi dkk, 2014).

Dalam Islam manusia diciptakan Allah SWT terdiri dari laki-laki dan perempuan dan akhirnya memiliki kebudayaan dunia yang berkaitan tentang tata cara hidup masing-masing dari mereka. Namun Allah mengingatkan agar manusia yang bertaqwa mengikuti perintah Allah dan menjauhi larangan-Nya untuk menjadi manusia yang paling mulia. Dalam mencapai derajat taqwa dan sekaligus menjadi manusia tentu tidak terlepas dari interaksi dengan orang lain dan alam sekitarnya (Adityangga: 2010). Seperti yang 
dijelaskan pada surat Al-Hujaraat ayat 13: yang artinya:

"Hai manusia, Sesungguhnya kami menciptakan kamu dari seorang laki-laki dan seorang perempuan dan menjadikan kamu berbangsa-bangsa dan bersuku-suku supaya kamu saling kenalmengenal. Sesungguhnya orang yang paling mulia diantara kamu disisi Allah ialah orang yang paling taqwa diantara kamu. Sesungguhnya Allah Maha mengetahui lagi Maha Mengenal" (QS. AlHujaraat: 13).

Menurut Shihab (2003) manusia adalah umat pada saat terjalinnya ikatan yang menghimpun mereka. Dengan demikian ayat ini menerangkan bahwa manusia diciptakan dari seorang laki-laki dan perempuan, untuk saling diperkenalkan dan dijadikan sukusuku kemudian menjadi bangsa-bangsa yang berbeda sehingga dapat membentuk budaya dengan kultur dan karakteristik yang berbeda pula. Budaya organsasi tidak bersimpangan dan bahkan tidaklah bertentangan dengan norma agama islam, akan tetapi islam memerintahkan kepada manusia untuk hidup saling berdampingan, saling berkompetisi, saling berbudaya dan bermartabat tinggi.

\section{Personal Values}

Menurut Loner \& Malpass (dalam Dayakisni, 2004), nilai melibatkan kayakinan umum tentang cara bertingkah laku yang diinginkan dan yang tidak diinginkan dan tujuan atau keadaan akhir yang diinginkan atau yang tidak diinginkan. Nilai adalah suatu keyakinan yang relatif stabil tentang model-model perilaku spesifik yang diinginkan dan keadaan akhir eksistensi yang lebih diinginkan secara pribadi atau sosial dari pada model perilaku atau keadaan akhir eksistensi yang berlawanan atau sebaliknya (Dayakisni, 2004).

Menurut Robbins (2015) memaknai nilai (value) yaitu keyakinan dasar bahwa sebuah mode tindakan spesifik atau akhir dari keberadaan lebih diinginkan secara pribadi atau sosial dibandingkan mode tindakan atau akhir keberadaan lawannya atau kebalikannya.

Sedangkan Krech (dalam Handayanto dkk, 2014) memaknai nilai (values) sebagai "an especially importance of belief concerning a value what is desirable of good or what ought to be" Rokeach (1973) mengatakan: "A value is personally or socially preferable to an opposite or end state of existence is personally or socially preferable to an opposite or converse model of conduct or end state of existence.

Secara bebas bisa diterjemahkan bahwa Nilai merupakan kepercayaan yang menetap yang lebih disukai sebagai cara bertindak (mode of conduct) atau mencapai tujuan (hidup) baik secara individual atau sosial dari pada cara-cara yang sebaliknya atau yang bertentangan".

Manusia dianjurkan eksplorasi alam dengan cara yang baik, penuh syukur dan tidak berlebihan, karena semua yang dipunyai manusia adalah milik Allah dan akan kembali pada Allah. Manusia hanya berusaha, Allah yang menentukan rezeki setiap umat manusia. Hal ini didukung oleh hadits yang menyatakan bahwa seorang yang memasuki pasar untuk berbisnis dan menyerahkan apa yang ia usahakan pada Allah maka Ia akan diberi kebaikan yang berlipat.

Rasulullah SAW bersabda: "Barang siapa memasuki pasar dan berkata: "Tidak ada Tuhan selain yang Esa, tiada yang menyamai, bagi-Nya kekuasaan, segala puji milik-Nya, zat yang menghidupkan dan mematikan, ia maha hidup, tidak akan mati, di tangan-Nya segala kebaikan, maha kuasa atas segala sesuatu, maka Allah akan menulis sejuta kebaikan dan menghapus sejuta keburukan, mengangkat sejuta derajat baginya".

Dari hadits itu dapat dipahami bahwa manusia adalah makhluk Allah yang diberi hati selain akal atau otak. Jika hatinya baik maka perilakunya akan baik, begitu sebaliknya jika hatinya jelek maka perilakunya juga akan jelek. Hati berfungsi membedakan yang baik dan yang buruk. Yang diinginkan dalam Islam adalah manusia yang mempunyai hati yang dapat membimbing dan mengatur otaknya sehingga perilakunya baik dan benar, bukan sebaliknya otak yang mengatur hatinya. Manusia juga diberi jasad dan cahaya serta nafsu, jika hati dikuasai oleh nafsu maka ia seakan-akan matanya buta, telinganya tuli dan hatinya tertutup, sehingga perilakunya pun akan jauh dari ajaran agama (Diana: 2012).

\section{Perilaku Ihsan}

Perilaku Ihsan mengandung dua makna. Pertama, memberikan kesenangan kepada orang lain. Kedua, melakukan pekerjaan yang terbaik (serius). Perilaku Ihsan dapat dilakukan dengan pengetahuan terbaik atau melakukan sesuatu sebaik mungkin (Ismail, 2011). Jadi Ihsan mengajarkan kita tiga hal Pertama, kita harus bekerja atau melakukan sesuatu 
sebaik mungkin (optimal) Kedua, kita harus berimprovisasi pengetahuan dan keterampilan terkait dengan tugas sehingga dapat bekerja secara optimal. Ketiga, kita harus menjauhkan diri dari bekerja asal-asalan atau tak terkendali karena tidak sesuai dengan keamanan dan Islam (Handayanto dkk, 2014).

Peneliti dalam mengukur (indikator) perilaku ihsan menggunakan atau berpedoman terhadap firman Allah surat Al-Qasas ayat: 77, yang artinya:

Dan carilah pada apa yang telah dianugerahkan Allah kepadamu (kebahagiaan) negeri akhirat, dan janganlah kamu melupakan kebahagiaanmu dari (kenikmatan) dunia dan berbuat baiklah (kepada orang lain) sebagaimana Allah telah berbuat baik kepadamu, dan janganlah kamu berbuat kerusakan di (muka) bumi. Sesungguhnya Allah tidak menyukai orang-orang yang berbuat kerusakan.

Dari ayat di atas dapat diambil kesimpulan bahwa perilaku ihsan dapat dinilai dengan cara: 1. Berusaha melakukan sesuatu agar mendapatkan kebahagiaan di dunia dan akhirat, 2. Berbuat baik kepada orang lain, dan 3. Tidak berbuat maksiat atau kerusakan di permukaan bumi.

Di dalam al-Qur'an kata Ihsan berarti "kebaikan" (QS. Ar-Rahman: 60) dan dapat berarti "berbuat kebaikan" (QS. An-Nahl: 90). Untuk lebih memperjelas pengertian Ihsan di atas, mari kita simak firman Allah pada surah an-Nisa', ayat 125 di bawah ini:

"Dan siapakah yang lebih baik agamanya dari pada orang yang ikhlas menyerahkan dirinya kepada Allah, sedang diapun mengerjakan kebaikan dan dia mengikuti agama Ibrahim yang lurus? Dan Allah mengambil Ibrahim menjadi kesayangan-Nya".

Sebagian ulama ahli tafsir dalam menjalankan ayat 125 surah an-Nisa' ini, mengatakan:

Tidak ada satu agama apa juga yang lebih bagus dari pada agama orang yang Islam atau menyerahkan wajahnya dengan ikhlas yang penuh kepada Allah dan melakukan kebajikan (berbuat ihsan) serta mengikuti agama Nabi Ibrahim yang hanief. Yang dikehendaki dengan kata berbuat ihsan di sini ialah melakukan segenap pekerjaan yang dikerjakannya itu dengan tulus ikhlas, bagus dan rapi, baik yang fardhu maupun yang sunnah.

Jadi Ihsan dapat dikatakan sebagai puncak kesempurnaan dari Iman dan Islam. Orang yang telah sempurna keimanan dan keislamannya akan mencapai suatu keadaan di mana ia dapat melakukan ibadah kepada Allah seakan-akan melihat Allah; dan bila tidak dapat demikian, ia akan selalu merasa diawasi oleh Allah.

\section{METODE}

Jenis penelitian yang digunakan adalah penelitian eksplanatori. Tujuan penelitian eksplanatori adalah untuk menjawab atau menjelaskan permasalahan yang sedang dihadapi. Malholtra (dalam Sani dan Maharani, 2013). Penelitian ini dilakukan di Rumah Sakit Islam Gondanglegi-Malang yang berlokasi di Jl. Hayam Wuruk No. 66, Gondanglegi Malang, Jawa Timur. Populasi adalah perawat Rumah Sakit Islam Gondanglegi Malang yang berjumlah 72 orang. Dengan menggunakan teknik Sampling jenuh, maka jumlah sampel yang digunakan sebesar 72 perawat.

Metode analisis yang digunakan adalah metode analisis jalur (Path Analysis). Model ini untuk mengetahui pengaruh langsung maupun tidak langsung variabel bebas (eksogen) (Sani \& Maharani: 2013). Dengan menggunakan path analysis maka tidak hanya menghitung secara simultan seluruh variabel bebas terhadap variabel terikat, tetapi juga dapat diketahui pengaruh secara parsial dari masing-masing variabel bebas terhadap variabel terikat. Path analysis atau analisis jalur digunakan untuk menganalisis pola hubungan diantara variabel. Model ini untuk mengetahui pengaruh langsung maupun tidak langsung seperangkat variabel bebas (eksogen) terhadap variabel terikat (endogen).

Untuk menguji signifikansi pengaruh tidak langsung dalam penelitian ini menggunakan uji sobel test dengan asumsi t hitung lebih besar dari pada t tabel. Nilai thitung ini dibandingkan dengan nilai t tabel yaitu $\geq 1,96$. Jika nilai t hitung lebih besar dari nilai t tabel maka dapat disimpulkan terjadi pengaruh mediasi (Ghazali, 2016).

\section{HASIL DAN PEMBAHASAN}

\section{Hasil}

Pengujian hipotesis parsial digunakan untuk menguji ada tidaknya pengaruh variabel eksogen secara parsial terhadap variabel endogen. Kriteria pengujian menyatakan bahwa apabila nilai probabilitas < level of significant $($ alpha $=\alpha)$ maka dinyatakan adanya pengaruh variabel eksogen secara parsial terhadap variabel endogen. Pengujian hipotesis dapat 
Tabel 1 Hasil Hipotesis Parsial

\begin{tabular}{lcccc}
\hline Eksogen & Endogen & Koef. & T statistics & Prob. \\
\hline Budaya Organisasi & Personal Values & 0.468 & 4.428 & 0.000 \\
Budaya Organisasi & Perilaku Ihsan & 0.441 & 4.083 & 0.000 \\
Personal values & Perilaku Ihsan & 0.261 & 2.410 & 0.019 \\
\hline
\end{tabular}

diketahui melalui ringkasan pada Tabel 1 berikut.

Pengaruh budaya organisasi terhadap personal values menghasilkan nilai $\mathrm{t}$ statistics sebesar 4.428 dengan probabilitas sebesar 0.000. Hasil pengujian tersebut menunjukkan bahwa probabilitas < alpha (5\%). Hal ini berarti terdapat pengaruh signifikan budaya organisasi terhadap personal values. Pengaruh budaya organisasi terhadap perilaku ihsan menghasilkan nilai t statistics sebesar 4.083 dengan probabilitas sebesar 0.000. Hasil pengujian tersebut menunjukkan bahwa probabilitas < alpha (5\%). Hal ini berarti terdapat pengaruh signifikan budaya organisasi terhadap perilaku ihsan.

Pengaruh personal values terhadap perilaku ihsan menghasilkan nilai t statistics sebesar 2.410 dengan probabilitas sebesar 0.019 . Hasil pengujian tersebut menunjukkan bahwa probabilitas < alpha
(5\%). Hal ini berarti terdapat pengaruh signifikan secara langsung personal values terhadap perilaku ihsan. Selanjutnya pengaruh budaya organisasi terhadap perilaku ihsan melalui personal values diketahui bahwa terdapat pengaruh signifikan budaya organisasi terhadap personal values, dan terdapat pengaruh signifikan personal values terhadap perilaku ihsan. Oleh karena kedua jalur signifikan maka dapat dinyatakan bahwa terdapat pengaruh yang signifikan budaya organisasi terhadap perilaku ihsan melalui personal values. Dengan demikian personal values mampu memediasi pengaruh budaya organisasi terhadap perilaku ihsan.

Adapun pengaruh secara langsung maupun secara tidak langsung sebagaimana disajikan dalam Tabel 2 berikut:

Tabel 2 Hasil Hipotesis Simultan

\begin{tabular}{|c|c|c|c|c|c|}
\hline \multirow[t]{2}{*}{ Eksogen } & \multirow[t]{2}{*}{ Mediasi } & \multirow[t]{2}{*}{ Endogen } & \multicolumn{3}{|c|}{ Koefisien } \\
\hline & & & Direct & Indirect & Total \\
\hline Budaya Organisasi & & Personal Values & $0.468 *$ & & 0.468 \\
\hline Budaya Organisasi & Personal Values & Perilaku Ihsan & $0.441 *$ & $0.122 *$ & 0.563 \\
\hline Personal Values & & Perilaku Ihsan & $0.261 *$ & & 0.261 \\
\hline
\end{tabular}

Koefisien pengaruh langsung budaya organisasi terhadap personal values sebesar $0.468^{*}$. Hal ini menunjukkan bahwa budaya organisasi berpengaruh positif dan signifikan terhadap personal values. Dengan demikian semakin baik budaya organisasi maka cenderung dapat meningkatkan personal values. Koefisien pengaruh langsung budaya organisasi terhadap perilaku ihsan sebesar $0.441^{*}$. Hal ini menunjukkan bahwa budaya organisasi berpengaruh positif dan signifikan terhadap perilaku ihsan. Dengan demikian semakin baik budaya organisasi maka cenderung dapat meningkatkan perilaku ihsan.

Koefisien pengaruh langsung personal values terhadap perilaku ihsan sebesar $0.261^{*}$. Hal ini me- nunjukkan bahwa personal values berpengaruh positif dan signifikan terhadap perilaku ihsan. Dengan demikian semakin tinggi personal values maka cenderung dapat meningkatkan perilaku ihsan. Koefisien pengaruh tidak langsung budaya organisasi terhadap perilaku ihsan melalui personal values sebesar $0.122 *$. Hal ini menunjukkan bahwa budaya organisasi berpengaruh positif dan signifikan terhadap perilaku ihsan melalui personal values. Dengan demikian semakin tinggi personal values yang disebabkan oleh budaya organisasi maka cenderung dapat meningkatkan perilaku ihsan. 
Uji Sobel atau Mediasi

Tabel 3 Uji Sobel Test

\begin{tabular}{ccccccc}
\hline \multirow{2}{*}{ Model } & & \multicolumn{2}{c}{ Unstandardized Coefficients } & \multirow{2}{*}{ T } & \multirow{2}{*}{ Prob } \\
\cline { 2 - 4 } & & \multicolumn{2}{c}{$\mathrm{B}$} & Std. Error & & \\
\hline $\mathrm{X}$ & $\mathrm{Z}$ &, 641 &, 161 & & \multirow{2}{*}{, 96} \\
$\mathrm{Z}$ & $\mathrm{Y}$ &, 510 &, 115 & 2,962 & 1,96 \\
\hline
\end{tabular}

Sumber: Data primer, diolah 2017

Dari penghitungan Uji sobel menggunakan software free sobel test versi 4.0 ditemukan nilai t hitung sebesar 2,962 yang artinya nilai tersebut lebih besar dari nilai t tabel 1,96. Hasil ini diperoleh dengan mengetahui dari analisis jalur (Path Analysis) pada tabel 4.15 diatas Model X ke Z menunjukkan angka 0,641 dengan standart error 0,161 sedangkan pada Model Z ke Y senilai 0,510 dengan standart error 0,115 sehingga dari perhitungan sobel test statistik menghasilkan nilai 2,962 sebagaimana terlampir pada lampiran. Jadi, hasil perhitungan sobel test statistik dengan nilai 2,962 > nilai t tabel yaitu 1,96. Sehingga variabel Personal Values (Z) memediasi variabel Budaya Organisasi $(X)$ terhadap variabel Perilaku Ihsan Perawat (Y).

\section{PEMBAHASAN}

\section{Pengaruh Langsung Budaya Organisasi Terha- dap Perilaku Ihsan Perawat}

Berdasarkan hasil pengujian hipotesis terdapat pengaruh yang signifikan Budaya Organisasi terhadap Perilaku Ihsan perawat. Hal ini di tunjukkan dengan hasil nilai t statistics sebesar 4.083 dengan probabilitas sebesar 0.000. Hasil pengujian tersebut menunjukkan bahwa probabilitas < alpha (5\%). Hal ini berarti terdapat pengaruh signifikan secara langsung budaya organisasi terhadap perilaku ihsan perawat. Selain itu, dari hasil analisis path dalam model pengukuran pada Tabel 1 menunjukkan koefisien pengaruh langsung budaya organisasi terhadap perilaku ihsan perawat sebesar 0.441. Hal ini menunjukkan bahwa budaya organisasi berpengaruh positif dan signifikan terhadap perilaku ihsan perawat. Dengan demikian semakin baik budaya organisasi maka cenderung dapat meningkatkan perilaku ihsan perawat.

\section{Pengaruh Budaya Organisasi Secara Tidak Langsung Ter hadap Perilaku Ihsan Perawat Melalui Variabel Personal Values}

Dari hasil penelitian menunjukkan bahwa terdapat pengaruh yang signifikan budaya organisasi terhadap perilaku ihsan perawat melalui personal values. Dilihat dari hasil analisis path dan uji sobel test. Budaya organisasi berpengaruh terhadap personal values. Hal ini berdasarkan jawaban responden menunjukkan bahwa instansi mendorong perawat untuk mempunyai gagasan baru dalam bekerja, atasan selalu menjaga hubungan yang harmonis dengan karyawan, perawat selalu mempertanggung jawabkan atas pekerjaan yang mereka lakukan, kebersamaan antar perawat yang baik, dan kegiatan kerja tidak hanya terfokus pada pekerjaan individu melainkan secara tim. Dari hasil jawaban responden menunjukkan bahwa perawat Rumah Sakit Islam Gondanglegi Malang dengan senang hati mengikuti budaya yang diterapkan oleh intansi, sehingga budaya organisasi berpengaruh terhadap personal values. Besarnya pengaruh budaya organisasi terhadap personal values ditunjukkan pada koefisien determinan sebesar $21.9 \%$ dan untuk koefisien regresi variabel budaya organisasi mempunyai arahan positif terhadap personal values. Didukung dengan hasil uji t secara parsial dengan taraf signifikan $5 \%$ terdapat pengaruh yang signifikan antara variabel budaya organisasi terhadap personal values.

Personal values berpengaruh terhadap perilaku ihsan. Hal ini ditunjukkan dari jawaban responden perawat mendapatkan ketenangan dalam melakukan pekerjaan, intansi dapat meningkatkan status sosial perawat meningkat, perawat merasa memiliki hubungan sosial yang lebih baik, perawat merasa bisa menambah hubungan dengan orang lain, dan perawat merasa bahwa semua pegawai yang ada di rumah sakit adalah keluarga. Sehingga personal values berpengaruh terhadap perilaku ihsan perawat. Besarnya 
pengaruh personal values terhadap perilaku ihsan perawat ditunjukkan pada uji t secara parsial yang menghasilkan 2.410 dengan taraf signifikan 5\% dan untuk koefisien regresi variabel personal values mempunyai arahan positif terhadap perilaku ihsan. Didukung dengan hasil uji diagram jalur secara parsial dan simultan yang menghasilkan terdapat pengaruh yang signifikan antara variabel personal values terhadap perilaku ihsan perawat. Dengan demikian semakin tinggi personal values yang disebabkan oleh semakin baiknya budaya organisasi maka cenderung dapat meningkatkan perilaku ihsan.

\section{KESIMPULAN}

Budaya Organisasi mampu meningkatkan Perilaku Ihsan Perawat. Hal ini dikarenakan karyawan diberi kesempatan untuk mengeluarkan pendapat, karyawan mempertanggung jawabkan atas pekerjaan yang mereka lakukan, intansi mendorong perawat untuk mempunyai gagasan baru dalam bekerja, atasan selalu menjaga hubungan yang harmonis dengan para karyawan. Dengan ini para perawat bersikap ramah dan sopan santun kepada orang lain, senang menolong orang lain, serta selalu menjaga diri dari perbuatan buruk, perawat rumah sakit melaksanakan tugas dengan baik dan ikhlas dalam memberikan pelayanan sehingga perilaku ihsan perawat meningkat.

Budaya Organisasi berpengaruh terhadap Perilaku Ihsan Perawat melalui Personal Values. Hal ini dikarenakan perawat merasa tenang dalam melakukan pekerjaan, perawat memperoleh rasa hormat dari orang lain, hubungan kehidupan sosial makin baik, dan hubungan kekeluargaan yang erat. Sehingga memunculkan perilaku ihsan perawat kepada pasien dan orang lain sekitar.

\section{Saran}

Bagi RSI Gondanglegi Malang diharapkan mampu meningkatkan personal values perawat, sehingga perawat merasa tenang dalam melakukan pekerjaan, terciptanya hubungan kehidupan sosial yang semakin baik.

Pimpinan RSI harus mampu menciptakan budaya organisasi yang kondusif, sehingga tercipta budaya kerja yang semakin baik. Pimpinan RSI juga harus mampu menumbuhkan perilaku ihsan perawat, sehingga perawat benar-benar menginginkan bekerja dan berkomitmen terhadap RSI.

\section{DAFTAR RUJUKAN}

Al-Qur'an Karim, Hadits dan Terjemahannya.

Adityangga, Krishna. 2010. Membangun Perusahaan Islam (Dengan Manajemen Budaya Perusahaan Islami). Jakarta: PT. Raja Grafindo Persada.

Dayakisni, Tri dan Salis, Yuniardi. 2004. Psikologi Lintas Budaya. Malang: UMM Pres.

Dessler, Gary. 2006. Manajemen Sumber Daya Manusia, Jilid 1. Jakarta: PT. Indeks.

Diana, Ilfi Nur. 2012. Hadits-hadits Ekonomi. Malang: UIN-MALIKIPRESS.

Ghozali, Imam. 2016. Aplikasi Analisis Multivariate dengan Program IBM SPSS. Semarang: Badan Penerbit Universitas Diponegoro

Handayanto dkk. 2014. The Effect of Organizational Culture, Leadership, Personal values. Volume 3 Issue 6. International Journal of Business and Management Invention.

Handayanto dkk. 2014. Using Organizational Culture, Leadership and Personal Values to Improve Ihsan Behavior at Masyithoh Hospital. Volume 3 Issue 8. International Journal of Business and Management Invention.

Ihsan, Sari. 2016. The Relationship between Organizational Culture and Innovative Work Behavior for Sports Services in Tourism Enterprises. Physical culture and sport. Studies and research.

Ismail, Asep Usman. 2011. Pengembangan diri menjadi pribadi mulia. Jakarta: Elex Media Kompatindo.

Luthans, F. 2006. Organizational behavior, tenth edition. Yuwono, VA. Purwanti, S. arie, P. Rosari, W. (penerjemah). Perilaku organisasi. Yogyakarta: Indonesia.

Narwal, Paramjeet. 2016. Personal Value and Organiztion Culture. Vol.03 Issue-03. International Journal in Commerce, IT \& Social Sciences.

Robbins, Stephen P \& Judge, Timothy A. 2015. Perilaku Organisasi, Edisi 16, Jakarta: Salemba Empat.

Shihab, M Quraish. 2003. Tafsir Al Mishbah; Jilid 15. Jakarta: Lentera Hati.

Supriyanto, Achmad Sani dan Vivin Maharani. 2013. Metodologi Penelitian Manajemen Sumber Daya Manusia: Teori, Kuesioner dan Analisis Data. Malang: UIN-MALIKI Press.

Thomas, Tammara Pertill. 2013. The effect of personal values, organizational Values, and person-organization fit on ethical Behaviors and organizational commitment Outcomes among substance abuse counselors: a Preliminary investigation. Tesis University of Iowa.

Umar, H. 2010. Desain Penelitian MSDM dan Perilaku Karyawan. Jakarta: PT. Raja Grafindo Persada.

Wirawan. 2007. Budaya dan Iklim Organisasi: Teori Aplikasi dan Penelitian. Jakarta: Salemba Empat. 